\title{
Discrimination contrast: Speeds to small reward as a function of locus and amount of Interpolated relnforcement'
}

FREDERICK R. MAXWELL, JR., PHILIP A. MEYER, ${ }^{2}$ RICHARD S. CALEF, and EARL R. MCHEWITT, Southern Illinois University, Carbondale, Ill. 62901

Three groups of rats $(C, D$, and $E$ ) each received, during a daily session, two runway trials in one-half of a differential conditioning apparatus to one-pellet reward. Groups $C$ and $E$ also received one and 12 pellets, respectively, in a placement cage twice during a session. Group D received two additional 12-pellet trials in the other half of the differential conditioning apparatus. The S- (one-pellet) speeds of Group D over the later stages of training were significantly below the approximately equivalent performance level attained by Groups $E$ and $C$.

Previous runway differential conditioning studies (cf. Bower, 1961; Ludvigson \& Gay, 1966) have shown that the speed with which a rat responds to a stimulus associated with a specific reward magnitude is affected by responding to stimuli associated with a reward of a different magnitude. Among such discrimination "contrast effects" (CEs), the observation of a negative S- CE, i.e., that the speeds of discrimination Ss in the alley associated with small reward (S-) are depressed relative to those of nondiscrimination Ss which always receive the identical small reward, is of particular interest in the present study.

In studies demonstrating a negative $\mathrm{S}-\mathrm{CE}$, discrimination (D) and control (C) Ss receive identical treatment on half of the daily trials. Thus, Ss in both conditions receive a small reward (e.g., one pellet) in one discriminandum (e.g., black alley) on, for example, two of four daily trials. The differential treatment between groups is administered on the remaining two trials of the day. D conditions receive a larger (e.g., 12-pellet) reward contingent upon traversing a different discriminandum (e.g., white alley). $\mathrm{C}$ conditions receive two additional one-pellet runway trials, either in the black (Bower, 1961) or white (Ludvigson \& Gay, 1966) alley. In these studies, the observation that D-condition speeds in the one-pellet discriminandum are depressed relative to those of C conditions may simply reflect the fact that Ss in the D conditions experience relatively large rewards while $S s$ in the $C$ conditions do not. Alternatively, this S-CE may reflect some more specific aspect of the differential treatment of $D$ and $C$ conditions, e.g., the administration of relatively large reward contingent upon runway traversal. The present study was concerned with whether experience with large reward, independent of the conditions under which this reward is obtained, is sufficient to depress runway speeds to a smaller reward magnitude.

\section{METHOD}

The Ss were 24 experimentally naive, male albino rats approximately 100 days old at the beginning of the experiment.

The runway apparatus consisted of a mid-grey 12-in. start box (SB) and two 42-in. alley-goal sections which were movable to permit alignment of either one with SB. One alley-goal section was painted black, the other white. The inner width of each section of the runway was 4 in., and the height $3 \frac{1}{2}$ in. throughout. A transluscent Plexiglas top covered all units. An opaque door separated SB from the alleys and transluscent guillotine-type retrace doors separated goal from alley sections. Photocell-clock circuitry provided traversal times over two consecutive 12-in. segments of the alley, beginning at the start door.

Fourteen days prior to the first day of training (Day 15), all Ss were placed on a 23-h food-deprivation schedule which was maintained throughout the study. On Days 5-14 Ss were taken from their individual home cages and handled for about $2 \mathrm{~min}$ each. On Days 13 and 14, Ss were also placed in individual carrying cages and taken to the experimental room where they were allowed to explore the start and run sections of the apparatus while clocks, photocells and doors were operated. On these days approximately $1 \mathrm{~g}$ of $45 \mathrm{mg}$ Noyes pellets, identical to the subsequent reinforcement pellet, was incorporated into Ss daily food ration.

Three randomly constituted groups of Ss each received, during a daily training session, two runway trials in which one pellet was available in a given goal box. The groups were differentially treated with respect to the nature of their further reward experience during a daily session. Group $D$ also received two 12-pellet trials in the other alley-goal section. Group E received 12 pellets twice during a session in a $10 \times 7$ $x$ 8-in. wiremesh open-top cage. Group $C$ received one pellet in the placement cage twice during a session. A total of 14 daily sessions were administered. The alley brightness associated with one pellet reward was counterbalanced within each group. Runway trials were administered to Group D according to the following repeating cycle of black (B) and white (W) trials: BWBW, WWBB, WBBW, BBWW, WBWB, BWWB. Ss were run in squads of six, one member of each subgroup in each squad. Cage placements for Groups $E$ and $C$ occurred in sequence with the 12-pellet trials for Group D. The order of running Ss, fixed within a day, changed from day to day. Trials were administered such that each $S$ in a squad received its first runway trial or cage placement before any $S$ received its second daily reward experience, etc. The time between reward experiences for any $S$ within a daily session was approximately $3 \mathrm{~min}$.

On a typical runway trial, the door separating SB from the alley was opened after $S$ had oriented for 3 sec toward the door. When $S$ entered the goal box, the retrace door was lowered. After $\mathbf{S}$ had eaten the pellet(s), it was removed from the goal box and replaced in the carrying cage. On cage placements, $S$ was removed from the carrying cage and placed into the cage. After eating the pellets, $S$ was returned to the carrying cage. Water was available at all times except in the runway or placement cage.

Traversal times ove; the first two 12-in. segments of the alley were reciprocated, yielding start and run speed measures. RESULTS

Group mean start and run speeds as a function of blocks of two daily sessions are presented in Fig. 1. Within each block of trials, the mean speeds for Group D on the two large reward (S+) trials are plotted separately from those obtained on small reward (S-) trials. As may be seen in Fig. 1, the S- speeds of Group D over the later stages of training were considerably below the approximately equivalent performance level attained by Groups $E$ and $C$. Analysis of variance of the speeds for Groups D, C, and E on S- trials over Blocks $6-7$ yielded significant group effects in both the start and run measures, $\mathrm{F}=6.42, \mathrm{df}=2 / 18, \mathrm{p}<.01$ and $\mathrm{F}=5.08, \mathrm{df}=2 / 18, \mathrm{p}<.05$, respectively. Subsequent $t$ tests revealed no significant 


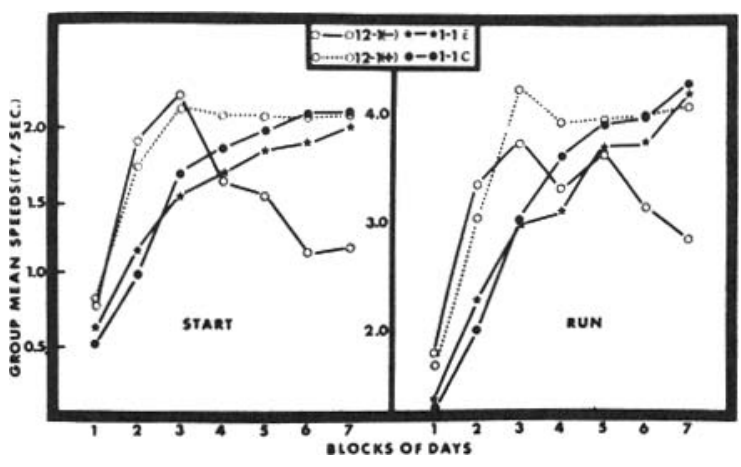

Fig. 1. Group mean start and run speeds for the various conditions as a function of blocks of two daily sessions.

differences between either the start or run speed means for Groups $\mathrm{E}$ and $\mathrm{C}$. However, Group $\mathrm{C}$ speeds were significantly faster than Group D speeds in both start and run measures $(p<.05)$. Group E speeds were significantly faster than Group D speeds in the start measure $(p<.05)$ and differed only slightly less significantly in the run measure $(p<.075)$. Finally, inspection of Fig. 1 indicates that Group D did form a discrimination, running faster on + than on - trials in the later stages of training. Analysis of variance of the data for Group D over Blocks 6-7 yielded a significant discrimination effect in both start and nun measures, $F=7.97$, $\mathrm{df}=1 / 6, \mathrm{p}<.05$ and $\mathrm{F}=8.51, \mathrm{df}=1 / 6, \mathrm{p}<.05$, respectively.

\section{DISCUSSION}

Considering the results of the present study with respect to speeds on one-pellet ( $\mathrm{S}-$ ) trials in the runway, at least two observations warrant attention. First, Group D, the discrimination group, ran significantly slower on one-pellet trials than did Group C. This finding is highly similar to the general phenomenon of negative $\mathrm{S}$ - contrast. Secondly, the performance levels of Groups $E$ and $C$ did not differ on one-pellet trials in the runway even though Group $\mathrm{E}$ received large (12-pellet) reward experience and Group $C$ did not. Taken jointly, these two findings demonstrate that depression of speeds to a stimulus associated with the smaller of two magnitudes of reward is not due merely to experience with larger reward magnitudes since both Groups $D$ and $E$ experienced large reward. Rather, these observations suggest that conditions under which the larger reward is experienced is important in producing a depression of $\mathrm{S}-$ speeds.

The findings of the present study, in conjunction with previous literature, indicate that merely receiving larger magnitude of reward is not sufficient to produce negative $S-$ contrast, but that contrast is produced when larger rewards are contingently experienced in the S+ runway. This indication seems relevant to the theoretical dichotomy made by Dunham (1968) between perceptual-motivational and emotionalmotivational interpretations of contrast. Generally speaking, the present data do not appear to support a perceptual interpretation of discrimination contrast. Insofar as the procedural differences between Groups $D$ and $E$ in the present investigation may be considered as contingent vs noncontingent reinforcement experience with larger magnitudes, the present results are consistent with a response (emotional) analysis of discrimination contrast.

\section{REFERENCES}

BOWER, G. H. A contrast effect in differential conditioning. Journal of Experimental Psychology, 1961, 62, 196-199.

DUNHAM, P. J. Contrasted conditions of reinforcement: A selective critique. Psychological Bulletin, 1968, 69, 295-315.

LUDVIGSON, H. W. \& GAY, S. E. Differential reward conditioning: Scontrast as a function of the magnitude of St. Psychonomic Science, $1966,5,289-290$.

\section{NOTES}

1. The authors are indebted to James H. McHose for advice and assistance throughout the course of the investigation which was supported by Research Grant MH 10340 from the United States Public Health Service.

2. Now at the University of South Dakota.

\section{(Continued from page 34)}

were somewhat unexpected. The number of UR sequences during acquisition was not the variable responsible for the magnitude of the PRE, although some UR sequences must be present for the PRE to occur. In the previous experiments the group with no UR sequences showed no PRE; however, when some UR sequences were present the effect occurred and some other variable must have been responsible for the magnitude of the effect.

Since percentage, number, and length of run of nonreinforcements were all confounded in the present experiment, theories emphasizing any of these variables as responsible for the magnitude of the PRE could account for the results of this experiment, although none can account for the differences between this experiment and the previous ones. Lawrence \& Festinger's (1962) dissonance theory would attribute the increased PRE to extra attractions which were developing during the increased number of nonreinforced trials, but this was not the case in the previous experiments, and when the nonreinforced trials were not followed by a reinforced one no PRE was present. Capaldi's (1966) emphasis on the length of run of nonreinforcements would explain the increased PRE in this experiment in terms of the longer length of runs of successive nonreinforcements, but again this increased PRE was not found in the previous experiments. With the small number of trials in this experiment predictions from Amsel's (1958) frustration explanation of the PRE would be indeterminate.
Since the previous conclusions were based upon a finding of no difference, the results may have been due to insensitivity, although differences were not even in the direction predicted by the other variables. Only the schedules of reinforcement were changed from the previous experiments and perhaps some subtle differences in the schedules are responsible for the magnitude of the PRE.

\section{REFERENCES}

AMSEL, A. The role of frustrative nonreward in noncontinuous reward situations. Psychological Bulletin, 1958, 55, 102-119.

CAPALDI, E. J. Partial reinforcement: A hypothesis of sequential effects. Psychological Review, 1966, 73, 459-477.

GROSSlighT, J. H., \& RADLOW, R. Patterning effect of the nonreinforcement-reinforcement sequence involving a single nonreinforced trial. Journal of Comparative \& Physiological Psychology, 1957, 50, 23-25.

KOTESKEY, R. L., \& STETTNER, L. J. Role of nonreinforcementreinforcement sequences in the partial reinforcement ef fect. Journal of Experimental Psychology, 1968. 76, 198-205.

LAWRENCE, D. H., \& FESTINGER, L. Deterrents and reinforcement. Stanford: Stanford University Press, 1962.

LEWIS, D. J. Partial reinforcement: A selective review of the literature since 1950. Psychological Bulletin, 1960, 57, 1-28. NOTES

1. This article is based on a dissertation submitted to Wayne State University in partial fulfillment of the requirements for the Ph.D. degree. The author wishes to thank Laurence Stettner for his advice and guidance during the entire investigation. The author held a NASA predoctoral traineeship grant during the investigation.

2. Now at Greenville College. 